\title{
J Ohn H. Sinnigen, Benito Pérez Galdós en la prensa mexicana de su tiempo. México, IIB, CEPE, UMBC,
}

UNAM, 2005.

El doctor J ohn Sinnigen es un profesor norteamericano que estudia la obra de Benito Pérez Galdós desde hace varios años, imparte cursos de literatura española eiberoamericana en la Universidad deMaryland en Baltimore, y se confiesa seducido por la cultura mexicana y fascinado por la ciudad de México. Esun buen amigo de este Centro de Enseñanza para Extranjeros y de nuestra Universidad. Tal vez al gunos de ustedes lo conocen bien. El doctor Sinnigen es él mismo un modelo intercultural y tan consciente es de ello que con ese enfoque realiza sus investigacionesy da sus cursos. A principios de este año salió a la luz su libro Benito Pérez Galdós en la prensa mexicana de su tiempo con el sello de nuestra Universidad, como explicaré más adelante. El análisis intercultural que proponeSinnigen en este libro, lo articula con base en lo que llama "la economía política de la cultura, esto es, las diferentes maneras en que la cultura, la política y la economía se condicionan mutuamente". La tesis del investigador se respal da en un amplio estudio bi bliohemerográfico y para el cual el Seminario de Bibliografía mexicana del sigl o XIX, que se desarrolla en el Instituto de Investigaciones Bibliográficas, tuvo la oportunidad de contribuir mediante el apoyo de uno de sus miembros, la maestra
Lilia Vieyra y los instrumentos diseñados por el seminario con el objeto de promover los trabajos bibliográficos vinculados con el siglo XIX mexicano y con la Biblioteca Nacional de México. Para Sinnigen si bien el fenómeno intercultural es histórico e inherente a la naturaleza humana, ha resal tado y cobrado un ritmo acelerado en los últimos años debido a la globalización. Al respecto opina: "Si bien el sistema capitalista mundial ha sido global, al menos desde el siglo XVI con la incorporación de las Américas en el sistema europeo, este carácter global se acentuado desde la caída del muro de Berlín y de la Unión Soviética, y la incorporación de los países del centro y este de Europa en un ampliado sistema capital ista. La fuerza de este movimiento gl obal izante ha tenido su debido impacto en el análisis cultural, así que Néstor García Canclini señala un cambio del paradigma de la definición de la cultura desde una perspectiva sociosemiótica y antropológica como son 'los procesos de producción, circulación y consumo de la significación en la vida social ' en una sociedad individual a otra, que supone el análisis relacional de la cultura, el que 'facilita hablar de la cultura como una dimensión que refiere a 'diferencias, contrastes y comparaciones [...]'" (p. 22). 
El análisis de la recepción dela obra de Galdós en México durante su vida es, para Sinnigen, un estudio intercultural en la medida que "se centra en la representación de un conjunto de textos donde el horizonte de expectativas era al mismo tiempo parecido y distinto del horizonte de la España del último tercio del siglo XIX". El impacto de las novelas y los dramas de Gal dós en nuestro país se presenta, además, como un fenómeno de apropiación cultural que trasciende el mero hecho literario, pensemos en los intentos de Victoriano Salado Álvarez y Enrique de Olavarría y Ferrari que siguen el model o de los Episodios nacionales del escritor español para narrar lo que era para ellos la historia más o menos inmediata de nuestro país. Pero vayamos más atrás y recordemos entonces que un joven escritor mexicano de 23 años compartía su "Viaje sentimental a San Ángel" con los lectores de la revista El Museo mexicano en 1843, mientras, al otro lado del Atlántico, en Las Palmas de Ia Gran Canaria, llegaba al mundo un hijo de Sebastián Pérez y Dolores Galdós que respondería al nombre de Benito. Curiosa coincidencia entre dos protagonistas de la gran novela decimonónica, exploradores de la real idad y del espíritu que contribuyeron al auge que tuvo el género a lo largo de la centuria. En su crónica de iniciación Manuel Payno, que nos obsequió quizás la mejor pintura del desconcierto imperante en México durante la primera mitad del siglo XIX con su novela Los bandidos de Río Frío, hace referencia a su lectura de Laurence Sterne, con lo cual revela un proceso de transferencia cultural que ahora nos permite estudiar la génesis de su obra y plantear diversos enfoques útiles para conocerla y val orarla. Dela misma forma, los testimonios, orientaciones o pistas que ofrecen los estudios sobre la recepción de un autor y su obra permiten, como sabemos, establecer sus alcances y significaciones en diferentes campos culturales (y no sólo en el de la historia de la literatura mexicana o en ella, si se concibiese como un registro total izador de la cultura escrita de nuestro país). El libro de Sinnigen prueba lo anterior y, como he anotado líneas arriba, demuestra la consistente presencia literaria de Benito Pérez Galdós en México. Lo que puede conducir a preguntarnos sobre su influencia en otras latitudes y en otros tiempos pues no de otra forma se construye y reconoce la trascendencia de las obras consi deradas universales. La respuesta, me parece, otorga al novelista español un sitio al lado de los grandes realistas que levantaron la épica de la burguesía decimonónica: Stendhal, Balzac, Flaubert, Tolstoi, Dostoievski, Thackeray, Dickens y sus coterráneos Leopol do Alas "Clarín", J osé María Pereda y J uan Valera.

La investigación de J ohn Sinnigen concluye que 35 libros de Gal dós fueron editadosen México entre 1874y 1899-Ma rianela, Gloria, Doña Perfecta, Lo Prohibido y Tormento tuvieron más de una edición en vida de su autor-; identifica las referencias a la obra del escritor canario y encuentra el gusto y los esfuerzos de I reneo Paz, Enrique de Olavarría y Ferrari y de Victoriano Salado Álvarez por aplicar la fórmula de los Episodios nacionales; el uso y abuso de textos galdosianos en el folletín de La Iberia, La Colonia española, La Voz de México, 
El Siglo diez y nueve, La Patria y El Nacional, entre otros periódicos; la crítica de escritores mexicanos como Emilio Rabasa, Francisco Sosa, Carlos Díaz Dufóo, Hilarión Frías y Soto y Manuel Gutiérrez Nájera - de los cual es rescata en el libro íntegramente las series de artículos de Sosa, Rabasa y Frías y Soto en uno de sus apéndices.

El autor está convencido de que para el galdosismo internacional, "el presente estudio cubre una laguna bi bliográfica, al mismo tiempo que aporta nuevos datos sobre los públicos lectores gal dosianos, y presenta por primera vez los análisis de distinguidos escritores mexicanos contemporáneos de obras de Galdós." En síntesis y en lo que concierne a los estudios mexicanos, Sinnigen encuentra que Gal dós fue el escritor extranjero más editado en México en el siglo XIX al revelar la fórmula de publicación de sus obras - es decir, la relación entre el folletín y el libro (y la piratería) - y poner en relieve la importancia que tuvo para la crítica literaria de su tiempo. (p. 29)

Sinnigen también resalta la presencia de textos de Galdós en los programas de español y literatura española moderna y contemporánea de nivel medio - secundaria y preparatoria-y se detiene en la relevancia que el novelista ha tenido en el cine mexicano: ocho películas inspiradas en obras suyas, entre ellas las inol vidables versiones de Doña Perfectay Nazarín, de Alejandro Galindo y Luis Buñuel, de 1950 y 1958, respectivamente, las otras son Adulterio, de J osé Díaz Morales (1943); El abueloy La loca de la casa, de J uan Bustillo Oro (1940), basadas en la novela y la obra teatral quellevan esosmismostítulos; Misericordia, de
Zacarías Gómez Urquiza (1952), de la novela homónima; La mujer ajena, de J uan Bustillo Oro (1954), adaptación de la novela y la obra dramática Realidad; Solicito marido para engañar, de Ismael Rodríguez (1987) que procede de la novela Lo prohibido, y Evangelio de las maravillas, de Arturo Ripstein, basada en el Nazarín de Buñuel. En esta permanencia o prolongación de las obras de Galdós en México hasta nuestros días también cabe mencionar que desde hace varios años la mayor parte de estos filmes se programan con relativa frecuencia en la televisión y que bien podríamos considerar las adaptaciones teatrales de los dramas galdosianos y las telenovelas que han explotado obras como Marianela, Gloria y Fortunata y J acinta. Materia toda esta con la cual ya Sinnigen prepara un estudio.

Miguel Ángel Castro IIB Y CEPE UNAM 
Decires Revista del Centro de Enseñanza paraExtranjerosse terminó de imprimir en los talleres de Navegantes de la comunicación gráfica S.A. de C.V., ubicados en Pascual Ortíz Rubio, núm. 40, Col. San Simón Ticumac, México, D.F., C.P. 03600, en el mes de junio de 2007. El tiro consta de 500 ejemplares.

Diseño de portada: Erandi Hernández Sierra. Diseño de interiores y formación electrónica: Sol Eréndira López Val dez. Cuidado de la edición: Ariadna G. Vaca Moro. 